\title{
Regulation of endothelial permeability in the primate corpora lutea: implications for ovarian hyperstimulation syndrome
}

\author{
Daniel Herr, Inga Bekes ${ }^{1}$ and Christine Wulff \\ Department of Obstetrics and Gynecology, University of Würzburg, Josef-Schneider-Str. 4, 97080 Würzburg, \\ Germany and ${ }^{1}$ Department of Obstetrics and Gynecology, Ulm University Medical Centre, Ulm, Germany \\ Correspondence should be addressed to D Herr; Email: daherr@gmx.de
}

\begin{abstract}
In a developing human corpus luteum, a closely regulated cellular communication system exists between the luteal steroidogenic cells and endothelial cells. This system guaranties the vascularization process during luteal formation. The process is combined with rapid release of large amounts of progesterone into the bloodstream. The regulation of endothelial proliferation and permeability by $\mathrm{LH}$ and human chorionic gonadotropin (hCG) is integral to this process. On the cellular level, endothelial permeability is regulated by intercellular junctions, such as adherens junctions (AJ) and tight junctions (TJ), which act as zipper-like structures between interacting endothelial cells. Several cell junctional proteins are localized to the corpus luteum, including Occludin, Nectin 2, Claudin 1, and Claudin 5, as well as, vascular endothelial (VE)-Cadherin. It has been assumed that regulation of AJ- and TJ-proteins is of particular importance for permeability, and accordingly, for the functionality of the corpus luteum in early pregnancy, because treatment with hCG induces downregulation of juntional proteins in the luteal vessels. The effect of hCG on the adhesive molecules is mediated by VE growth factor (VEGF). On a functional level, the hCG-dependent and VEGF-mediated decrease in junctional proteins causes a decrease in the density of cell-cell closure and, accordingly, an increase in endothelial permeability. In doing so, the different junctional proteins are not only directly influenced by VEGF but also interact among themselves and influence each other reciprocally. Disturbances in this strictly, regulated interactions may explain the development of pathologies with increased vascular permeability, such as the ovarian hyperstimulation syndrome.
\end{abstract}

Reproduction (2015) 149 R71-R79

\section{Introduction}

The corpus luteum is a transitory active endocrine gland undergoing cyclic growth and degeneration. It plays a central role in the maintenance of pregnancy. The preovulatory luteinizing hormone (LH) surge causes ovulation and rapidly initiates the transformation of ovulated follicle into corpus luteum. Thus resulting in progesterone synthesis, which is essential for implantation and maintenance of gestation (Stocco et al. 2007). In primates, if pregnancy does not occur, regression of the corpus luteum occurs 14 days after ovulation. However, in case of pregnancy, the survival of the corpus luteum is dependent on the effect of human chorionic gonadotropin (hCG) synthesized in the placenta (Matsubara et al. 2000, Baird et al. 2003, Duncan et al. 2005, Del Canto et al. 2007, Dickinson et al. 2008, 2009). In the absence of pregnancy, maintenance of the mid-luteal corpus luteum can be achieved by administration of iatrogenic exogenous hCG (Illingworth \& Heap 1971). In addition to fibroblasts, pericytes, and immune cells, the corpus luteum consists of endothelial cells, granulosa lutein cells, and theca lutein cells (in non-primates, the latter are often also called small or large steroidogenic luteal cells). Granulosa lutein cells are capable of triggering angiogenesis, by causing sprouting from proximal blood vessels to obtain nutrients, oxygen, and hormone precursors: all of which are necessary to produce large amounts of progesterone (Fraser \& Lunn 2001). Along with the necessary angiogenesis for progesterone synthesis, the permeability of luteal vessels must be tightly regulated. This regulation ensures the entry of nutrients, oxygen, and hormone precursors into the tissue, as well as, the release of progesterone from the tissue into the vessels. The responsible factors for controlling vascular permeability are thereby endothelial cells and cell-celljunctions. Permeability is mediated by strictly regulating the opening and closing of the cell-cell junctions (Bazzoni \& Dejana 2004, Dejana 2004, Walz et al. 2005). Therefore, any disturbance in junctional organization might result in an inadequate endothelial function, leading to pathological conditions, due to 
vessel wall structural modification. Typical clinically important examples caused by increased vascular permeability are edema and ovarian hyperstimulation syndrome (OHSS), which includes abdominal bloating and feeling of fullness, nausea, diarrhea, and slight weight gain, and which is associated with assisted reproduction (Delvigne \& Rozenberg 2003). During assisted reproduction procedures, hCG administration is used to induce ovulation and luteinization of the ruptured follicles thus enhancing the risk of OHSS (Fatemi et al. 2007). This syndrome is characterized by increased capillary permeability leading to leakage of fluid from the vascular compartment (Delvigne \& Rozenberg 2002). Therefore, further understanding of the molecular regulation of the corpus luteum might help in the treatment of OHSS not only symptomatically but also influencing the causal connection. This review aims to summarize the cellular regulation of endothelial permeability in primate corpora lutea and its implication on OHSS.

\section{Basics of cell-cell communication and molecular regulation of endothelial permeability}

Endothelial cells function as doormen, regulating the transfer of molecules into the vasculature and the underlying tissue. In addition, diverse junctions also have a key regulatory function such as gap junctions, adherens junctions (AJ), and tight junctions (TJ). Gap junctions are intercellular connections between cells, connecting the cytoplasm of two cells directly, thus allowing various molecules and ions to pass freely between cells (Lampe \& Lau 2004). Regarding the regulation of paracellular permeability, at least two different types of intercellular junctions are involved: the $\mathrm{AJ}$ and TJ. These junctions are localized in the lateral cell membrane between neighboring endothelial cells (Fig. 1), sealing the space between the cells. The AJ and TJ are formed by different families of transmembrane proteins that promote homophilic cell-cell interactions and transfer of intracellular signals (Dejana et al. 2009a). Many reports support the concept that intercellular junctions are dynamically remodeled not only in embryogenic cells, but also in resting cells (Dejana et al. 2009b). Adhesive membrane proteins of AJ and TJ form adhesive complexes, which act as zipper-like structures between interacting cells (Nelson \& Veshnock 1987, Yap et al. 1997, Chitaev \& Troyanovsky 1998, Cavey et al. 2008). These proteins are localized hierarchically from the apical to the basal pole of the lateral membrane. In the most apical position, the Claudin TJ protein family is localized followed by Occludin and the Nectin family (Morita et al. 1999). Unlike the TJ, the AJs are localized more basal than apical, mainly consisting of the cadherin family (Fig. 1). The endothelial cells express tissue-specific

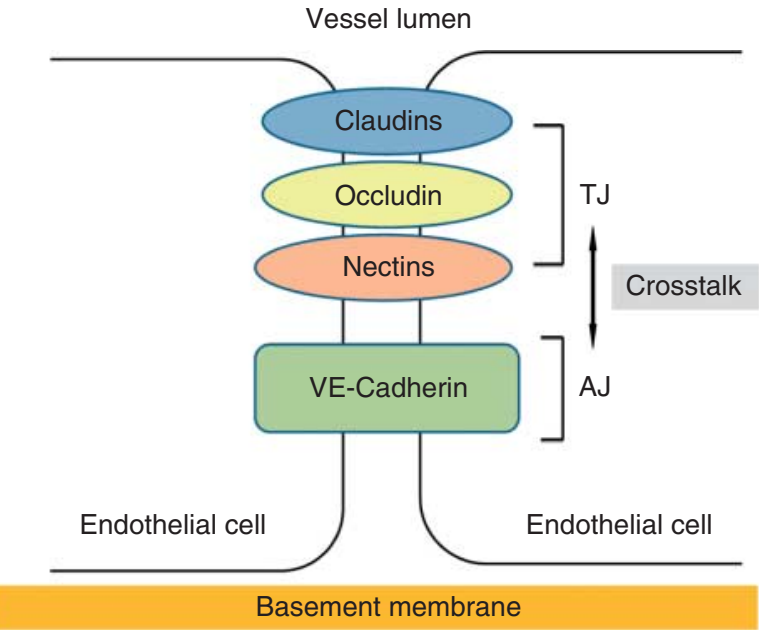

Figure 1 Schematic distribution of TJ and AJ in endothelial cells. Distribution of TJ and AJ proteins including Claudins, Occludins, Nectins, and VE-Cadherin between two endothelial cells from apical to basal. It must be pointed out that a crosstalk mechanism operates between these junctional structures.

transmembrane adhesion proteins: the AJ vascular endothelial (VE)-Cadherin, the TJ Claudin 5, and the TJ Nectin 2 (Nitta et al. 2003, Dejana 2004, Herr et al. 2013). VE-Cadherin and Claudin 5 are key the components of adherens and tight endothelial junctions respectively. It has been suggested that VE-Cadherin controls Claudin 5 expression by preventing the nuclear accumulation of FOXO1 and $\beta$-catenin, which repress the Claudin 5 promoter. This indicates that a crosstalk mechanism operates between these junctional structures (Gavard \& Gutkind 2008; Fig. 1). Knockdown of Claudin 5 in mice is associated with normal embryological development, yet due to a defective blood-brain barrier function, the Claudin 5-deficient mice die shortly after birth (Nitta et al. 2003). In comparison, VE-Cadherin deficient mice experience severe lethal defects during developmental angiogenesis (Carmeliet et al. 1999). This suggests a role for VE-Cadherin going far beyond promoting only structural functions between endothelial cells. In addition to VE-Cadherin and Claudin 5 interactions, the Nectin-system has recently been described as a novel modulator of $\mathrm{AJ}$ and TJ. Nectin consists of at least four members (Nectin 1-4). However, the focus of this paper is on Nectin 2, because it is the only member of the Nectin system that could be localized to the endothelium of the granulosa lutein compartment of the primate corpus luteum (D Herr, I Bekes and C Wulff, unpublished observation).

\section{Distribution of cell junctional proteins in the human corpus luteum}

The distribution of $\mathrm{TJ}$ and $\mathrm{AJ}$ in the primate $\mathrm{CL}$ is summarized in Table 1. Different cell junctional 
Table 1 Distribution of junctional proteins in the primate corpus luteum based on immunolocalization of TJ and $\mathrm{AJ}$ proteins in the $\mathrm{CL}$ from the mid-luteal stage (Groten et al. 2006, Herr et al. 2013).

\begin{tabular}{|c|c|c|c|c|}
\hline Protein & $\begin{array}{l}\text { Endothelium } \\
\text { (granulosa } \\
\text { compartment) }\end{array}$ & $\begin{array}{l}\text { Endothelium } \\
\text { (theca } \\
\text { compartment) }\end{array}$ & $\begin{array}{l}\text { Granulosa } \\
\text { lutein } \\
\text { cells }\end{array}$ & $\begin{array}{l}\text { Theca } \\
\text { lutein } \\
\text { cells }\end{array}$ \\
\hline Occludin & Present & Present & Present & Present \\
\hline Claudjn 1 & Absent & Absent & Present & Absent \\
\hline Claudin 5 & Present & $\begin{array}{l}\text { Present } \\
\quad \text { (large } \\
\text { vessels) }\end{array}$ & Absent & Absent \\
\hline VE-Cadherin & Present & Present & Absent & Absent \\
\hline Nectin 2 & Present & Absent & Absent & Absent \\
\hline
\end{tabular}

proteins are localized in the mid-luteal human corpus luteum, including the TJ proteins Occludin, Claudin 1, Claudin 5, and Nectin 2, as well as the AJ protein VE-Cadherin (Groten et al. 2006, Herr et al. 2013). The distribution of these cell-cell contacts varies in different cellular compartments within the corpus luteum. In humans, Occludin is continuously localized in the plasma membrane of endothelial cells of midluteal granulosa lutein and theca capillaries as well as in the granulosa lutein cells itself. However, Occludin could not be detected in the theca lutein cells (Groten et al. 2006). The presence of Occludin in epithelial and endothelial cells has also been discovered in other species tissues, such as rat lung, human liver, mouse brain, and others (Langbein et al. 2002, Leach et al. 2002, Butt et al. 2012, Errede et al. 2012, You et al. 2012).

On the other hand, Claudin 1 is exclusively localized in the plasma membrane of granulosa lutein cells. Unlike the Occludin, which has a continuous belt-like formation, Claudin 1 during early-, mid-, and late-luteal phases of the human corpus is discontinuous (Groten et al. 2006). This distribution is similar to that seen in the human ovarian surface epithelium (Zhu et al. 2004). However, Claudin 1 is unexpressed in the luteal endothelial compartment. This is different compared with endothelial cells of the brain and of rat salivary glands (Fujibe et al. 2004, Peppi \& Ghabriel 2004). In contrast to Claudin 1, Claudin 5 is exclusively localized in the endothelial compartment of the human corpus luteum (Groten et al. 2006). Claudin 5 is mainly expressed in capillaries and in large vessels of the theca endothelium (Groten et al. 2006). However, VE-Cadherin occurs in both, capillary endothelium of the granulose lutein and theca compartment of the corpus luteum (Groten et al. 2006). There is no exact explanation for the varied regulated expression of those molecules, yet it is clear that in diverse cellular compartments a certain combination of various adhesion and junctional proteins are responsible for cell-cell communication and adhesion (Groten et al. 2006; Table 1).

\section{Functional influence of hCG on cell junctional proteins in the human corpus luteum}

The cyclic growth and differentiation of the corpus luteum are regulated by gonadotropins (Fraser et al. 1999, Fraser \& Lunn 2000, Wulff et al. 2001a, Fraser \& Duncan 2005). Within normal cycle, influenced by LH, the lifespan of the primate corpus luteum is generally restricted to 14 days. However, in case of pregnancy, due to hCG, it survives several months, which is called 'luteal rescue'. For the human corpus luteum, it has been demonstrated that luteal rescue is associated with the expansion of luteal vessels (Wulff et al. 2001a), which probably includes the re-arrangement of cell-cell contacts such as junctional proteins. Therefore, it is of high interest to focus on hCG-dependent regulation of $\mathrm{TJ}$ and $\mathrm{AJ}$ in human corpus luteum.

In the rescued human corpus luteum of simulated early pregnancy (women had received hCG exogenously), Claudin 1 and Occludin are significantly downregulated in the granulosa lutein compartment (Groten et al. 2006). Furthermore, luteal rescue by hCG induced a decrease in Occludin, Claudin 5, and VE-Cadherin in the endothelial cell compartment of human corpora lutea (Groten et al. 2006). This observation is in line with studies in rats in which hCG deceased the expression of Claudin 5 mRNA (Kitajima et al. 2006), which was associated with increased vascular permeability (Albert et al. 2002, Kitajima et al. 2006).

It has been assumed that regulation of $\mathrm{AJ}$ and $\mathrm{TJ}$ proteins is highly important for supporting the corpus luteum function in the maintenance of early pregnancy. Downregulation of cell junctions may be required to increase intercellular space, ensuring invasion and expansion of new vessels within the granulosa lutein cell compartment, and it may also be required for increasing endothelial permeability in the vascular compartment (Rodewald et al. 2007) to be able to release and uptake molecules such as progesterone or VE growth factor (VEGF) (Wulff et al. 2000). This increase may facilitate the distribution of hormones needed for the maintenance of early pregnancy.

\section{Influence of VEGF on cell junctional proteins in the primate ovary}

It has been shown that hCG decreases the amount of cell-cell adhesion molecules with its above-described effects on luteal angiogenesis and permeability. In addition, as inhibition of VEGF has major hindering effects on ovarian angiogenesis, development, and function (Wulff et al. 2001 b, 2002, Taylor et al. 2007), there are data supporting the hypothesis that VEGF controls cell junctional proteins in the mid-luteal phase of the primary corpus luteum of the marmoset (Rodewald et al. 2007). The TJ protein Occludin is localized to the plasma membrane of granulosa cells 
(Rodewald et al. 2007). In primates (marmoset), during follicular development, the amount of Occludin decreases continuously and disappears completely at the ovulatory stage (Rodewald et al. 2007). The loss of Occludin may be involved in antrum formation, because antrum formation involves alteration in granulosa cellcell adhesion and sealing. This observation is supported by immunoblot studies in rat and mouse granulosa cells of antral follicle, showing decreased amount of adhesion molecules (Sundfeldt et al. 2000, Kawagishi et al. 2005).

However, inhibition of VEGF in marmoset in vivo, by treating with VEGF-antagonist VEGF-trap leads to a significant increase in Occludin (Rodewald et al. 2007). Thereby, focus of the staining is the cytoplasm. Nevertheless, the percentage of the protein which is localized in the cytoplasm is non-functional (Alexander \& Elrod 2002). Accordingly, inhibition of normal vascular development severely affects cell-cell adhesion and communication in the granulosa compartment through the disruption of Occludin-delineated TJ (Schmitt et al. 2004).

The TJ protein Claudin 5 in the marmoset follicle is exclusively localized to vessels of the theca cell compartment, and the amount of protein increases during follicular development (Rodewald et al. 2007). During mid-luteal corpus luteum, Claudin 5 is also present in the vasculature and an increase in Claudin 5 results from inhibition of VEGF by a VEGF trap. Evidently, Claudin 5 plays a role in contact-inhibition of endothelial cells, thus decreasing the endothelial cell proliferation and the vessels being stabilized (Rodewald et al. 2007). As soon as endothelial cells are in contact with the neighboring cells, the adhesion molecules link together and the cells become less affected by the proangiogenic effect of VEGF (Rodewald et al. 2007). Celladhesion is crucial for angiogenesis regulation (Nakhuda et al. 2005). It has been shown, that inhibition of VE-Cadherin is followed by suppression of angiogenesis and degeneration of the vascular compartment in the mid-luteal phase corpus luteum (Nakhuda et al. 2005). VEGF acts as a key molecule for the regulation of angiogenesis in the ovary (Wulff et al. 2000, $2001 a, b, c$, 2002). In addition, a close interrelation has been shown between VEGF and adhesion signaling pathways. Endothelial AJ are a downstream target of VEGFR2 signalling suggesting to be involved in the modulation of endothelial permeability (Esser et al. 1998). Therefore, it is reasonable that inhibition of VEGF in vivo affects the Claudin 5 protein localization and expression in the ovary (Rodewald et al. 2007).

\section{Cell junctional proteins and permeability}

Recently, using endothelial cells (HUVEC) in an in vitro model, it has been suggested that hCG may have a direct effect on endothelial permeability and VE-Cadherin expression (Villasante et al. 2007). However, the meaning and signaling of an assumed endothelial cell $\mathrm{LH} / \mathrm{hCG}$ receptor are unclear. It is most likely that the receptor has a hormone transcytosis function, meaning that the gonadotropin can be delivered through the endothelium to the target cell (Misrahi et al. 1996). In order to investigate the cellular regulation of endothelial cells in the corpus luteum, an in vitro human cell co-culture representation was developed as a model for studying the effects of stimulatory agents on endothelial and granulosa lutein cells, as well as the molecular interactions between those cells (Rodewald et al. 2009). It has been previously published that during simulated maternal recognition of pregnancy, there is a decrease in luteal endothelial Claudin 5 protein in the presence of hCG (Groten et al. 2006). Moreover, a paracrine effect of hCG on endothelial Claudin 5, as well as on endothelial permeability, was observed in the presence of granulosa lutein cells (Rodewald et al. 2009). The major effect of hCG on endothelial permeability and Claudin 5 expression remains indirect, occurring only in the presence of granulosa lutein cells. Therefore, an hCGdependent factor secreted by granulosa lutein cells was likely to be responsible, and this factor effecting endothelial cells is VEGF. Indeed, hCG stimulation of granulosa lutein cells increased VEGF protein production, as has been shown in previous papers (Neulen et al. 1998, Fraser et al. 2005, Rodewald et al. 2009). In addition, hCG has been demonstrated to trigger VEGF expression in human luteal steroidogenic cells in vivo (Wulff et al. 2001c). Increased levels of VEGF are capable of acting directly on neighboring endothelial cell (Rodewald et al. 2009). The regulatory function of VEGF on endothelial cell permeability has previously been shown in cell culture experiments (Albert et al. 2002, Villasante et al. 2007). In vivo, VEGF caused increased fenestration and defect in liquid tightness of vessels, as well as angiogenesis of rodent muscle cells (Zacchigna et al. 2007). VEGF is therefore a strong candidate for the paracrine effects on endothelial cell permeability. It is likely that this is mediated through the regulation of adhesion proteins (Wright et al. 2002, Lampugnani et al. 2006). In addition, it has been shown that inhibition of the VE-Cadherin system using antibodies in vivo can inhibit angiogenesis, an vascular permeability in rat ovary (Nakhuda et al. 2005). Indeed, VEGF increases Claudin 5 release in endothelial cells, which is associated with increased permeability (Rodewald et al. 2009). This finding indicates a direct link between hCG, VEGF, Claudin 5, and increased endothelial permeability.

It should be noted that the effects of VEGF synthesized in ovary not only affect ovarian vessels but may also influence the permeability of the vasculature of other organs. Such effects are observed in peritoneal vessels, resulting in ascites or edema, which have implications in disorders such as ovarian cancer (Herr et al. 2012) 
or OHSS. The latter is discussed in the last section of this review.

\section{Interactions of cell junctional proteins in endothelial cells}

On a structural level, functional interactions of junctional proteins acting as regulators of vascular permeability are present in several systems such as the blood-brain-barrier and the peritoneum (Akutagawa et al. 2002, Willis et al. 2013). Despite the fact that the corpus luteum is among the most highly vascularized tissues, and vascular permeability is likely to play a critical role in its function, these mechanisms are relatively unexplored in the corpus luteum. Junctional proteins are dynamic structures undergoing uninterrupted rearrangement during embryonic development.

Obviously, there is a flow-like movement in a basalapical direction. Such movement also occurs in resting cells, such as normal epithelial sheets, but solely at the junctions formed by moving cells (Kametani \& Takeichi 2007). These highly dynamic intercellular junctions interact in order to control vascular permeability in response to outside signals (Furuse \& Tsukita 2006, Van Itallie \& Anderson 2006). Consecutively, co-existence of those proteins has been described for different tissues in different species, especially concerning the expression of $\mathrm{AJ}$ and $\mathrm{TJ}$ in the vascular system of the human corpus luteum (Herr et al. 2013). The AJ protein VE-Cadherin and the TJ protein Nectin 2 and Claudin 5 are co-localized in the vasculature of the mid-luteal human corpus luteum (Herr et al. 2013). hCG treatment of granulosa lutein in co-culture with endothelial cells decreases the production of VE-Cadherin, Nectin 2, and Claudin 5 proteins in the endothelial cells (Herr et al. 2013). Thereby, this in vitro effect is mediated by VEGF. The reciprocal influence of VE-Cadherin, Nectin 2, and Claudin 5 as regulators of permeability in endothelial cells has been investigated in vitro as follows: the downregulation of VE-Cadherin or Claudin 5 induces a decrease in the respective alternate proteins, whereas knockdown of Nectin 2 does not influence VE-Cadherin and Claudin 5 (Herr et al. 2013). Those changes in the junctional proteins not only remain on a structural level but can also be translated in functional alterations. hCG-induced downregulation of junctional proteins results in an increased rate of endothelial permeability in vitro (Herr et al. 2013). In addition, switching off of VE-Cadherin, Nectin 2, and Claudin 5, performing an siRNA knockdown, causes a successive increase in endothelial permeability of each different protein (Herr et al. 2013), thus demonstrating its important role in the functionality of the human corpus luteum.

These results indicate that VE-Cadherin and Claudin 5 play a major role in the regulation of endothelial permeability via Nectin 2. In addition, Nectin 2 also

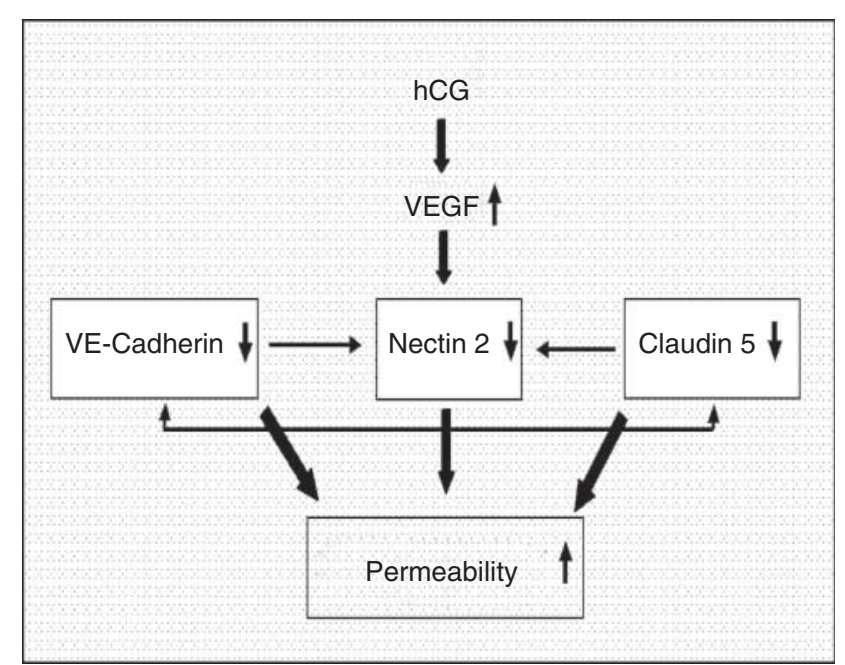

Figure 2 Schematic of the regulation of endothelial permeability in the primate corpus luteum: hCG upregulates VEGF, which causes a decrease in the cell-cell adhesion proteins. In addition, Claudin 5 and VE-Cadherin influence each other. As a consequence, this causes an increase in endothelial permeability.

influences vascular permeability directly. However, the opposite pathway of Nectin 2-dependent, VE-Cadherin, and Claudin 5 expression/production seems to be inexistent. As these three proteins are co-localized in the vessels of the human corpus luteum and downregulated by hCG via VEGF actions, we hypothesize that hCG induces a chain reaction by downregulating VE-Cadherin and/or Claudin 5, which interact with other adhesion proteins such as Nectin 2 consecutively resulting in increasing luteal permeability (Herr et al. 2013; Fig. 2).

\section{Clinical implications: the OHHS}

The OHSS (Fig. 3) is a complication that is observed in women undergoing assisted reproduction procedures. Severe OHSS occurs in $\sim 1.4 \%$ of all cycles (Klemetti et al. 2005). VEGF plays a key role in the pathogenesis of OHSS. During assisted reproduction, multiple-follicular growth is induced by follicle-stimulating hormone to obtain a sufficient number of fertilizable oocytes. Thus, ovulation is induced by hCG treatment, which is followed by luteinization of preovulatory follicles. Accordingly, multiple corpora lutea are formed, which synthesize VEGF. VEGF is then released into the blood stream in turn causing highly elevated levels of VEGF in OHSS patients (Pietrowski et al. 2012). Owing to two waves of VEGF, the OHSS occurs as an early-onset form in response to exogenously dispensed hCG, as well as late-onset form (Fig. 4).

In this case, hCG is secreted from the implantation pregnancy and may be associated with the conception cycles, especially multiple pregnancies, and is more likely to be severe (Papanikolaou et al. 2005). 


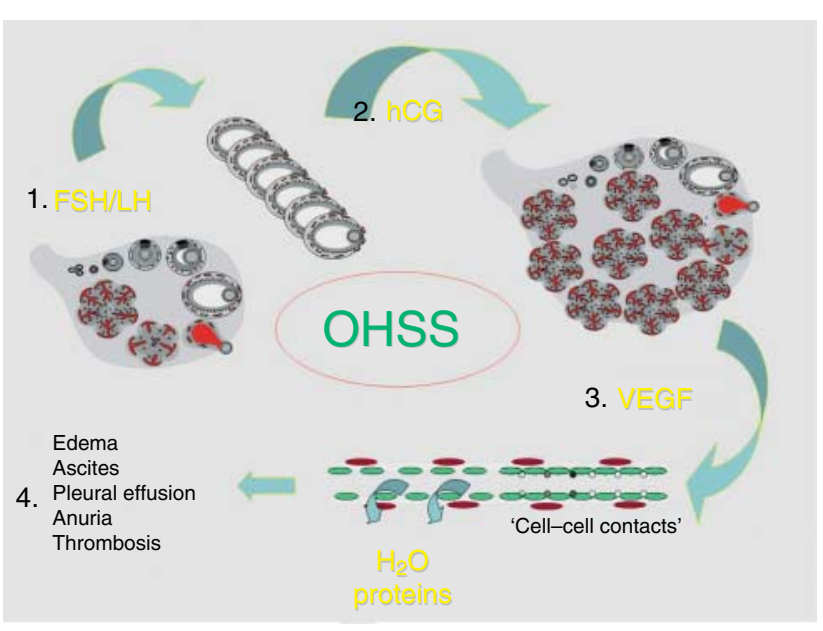

Figure 3 Pathogenesis of the OHSS: (1) FSH/LH control the folliculogenesis in the ovary. (2) hCG stimulates granulosa lutein cells in the corpus luteum and causes an increase in VEGF. (3) VEGF subsequently decreases the cell-cell adhesion molecules of the endothelium and thereby raises the endothelial permeability which finally causes (4) clinical signs such as edema, ascites, and pleural effusion.

Furthermore, VEGF is released locally into the abdominal cavity (van de Lagemaat et al. 2011). Both may affect junctional proteins in peripheral vessels such as the peritoneal vasculature. In this case, VEGF may suppress junctional proteins in the endothelium. Recent data have shown that these junctional proteins interact with each other (Herr et al. 2013). This suggests that increase in vascular permeability is enhanced, leading to loss of fluid in the extracellular space and, as a result, causing all symptoms of OHSS, including ascites and edema. In addition, VEGF originating from the ovary has been assumed to be responsible for the development of pleural effusion (Wang et al. 2002).

From a therapeutical point of view in patients with OHSS, gonadotropin-releasing hormone agonists can modulate vascular permeability via influencing the expression of the TJ protein Claudin 5 (Kitajima et al. 2006). Furthermore, in patients at risk of OHSS, the effect of VEGF on junctional proteins can be also inhibited by dopamine agonists, thus decreasing vascular permeability (Gomez et al. 2011, Kumar et al. 2011, Soares 2012). Several lines of evidence have also implicated dopamine as an etiological factor in the OHSS. However, to date, evidence has failed to support this contention (Gelety \& Chaudhuri 1992). Therefore, a therapeutical perspective concerning the treatment of the OHSS might be influencing increased permeability in those patients via targeting VEGF. One corpus luteum should be enough to preserve pregnancy. Local treatment such as transvaginal injection of several corpora lutea with VEGF-antagonists may be considered. Currently, we are far from providing a concrete therapeutical option, because the pro-angiogenic effects of VEGF are urgently needed in pregnant women to maintain pregnancy. Occasionally, in patients with severe complications, induced abortion is performed in order to protect the health of the pregnant mother. However, in those cases, anti-VEGF treatment might be a better therapeutical option, with the potential to preserve the health of the patient along with her pregnancy.

\section{Summary}

Among others, the primate corpus luteum is regulated by cellular communication between luteal steroidogenic cells and endothelial cells, resulting in angiogenesis associated with luteal formation. Essential for this process is the tight control of the endothelial permeability. The luteal endothelial cells thereby express several AJ and TJ, such as Occludin, Claudin 1, Claudin 5, Nectin 2, and VE-Cadherin. It has been shown in vitro, as well as in vivo, that hCG induces downregulation of those junctional proteins in the luteal vessels via VEGF. An increased level of VEGF results in raised endothelial permeability in the corpus luteum and in the peritoneal vessels outside the ovary. Accordingly, this helps to ensure the supply of nutrients in the corpus luteum and
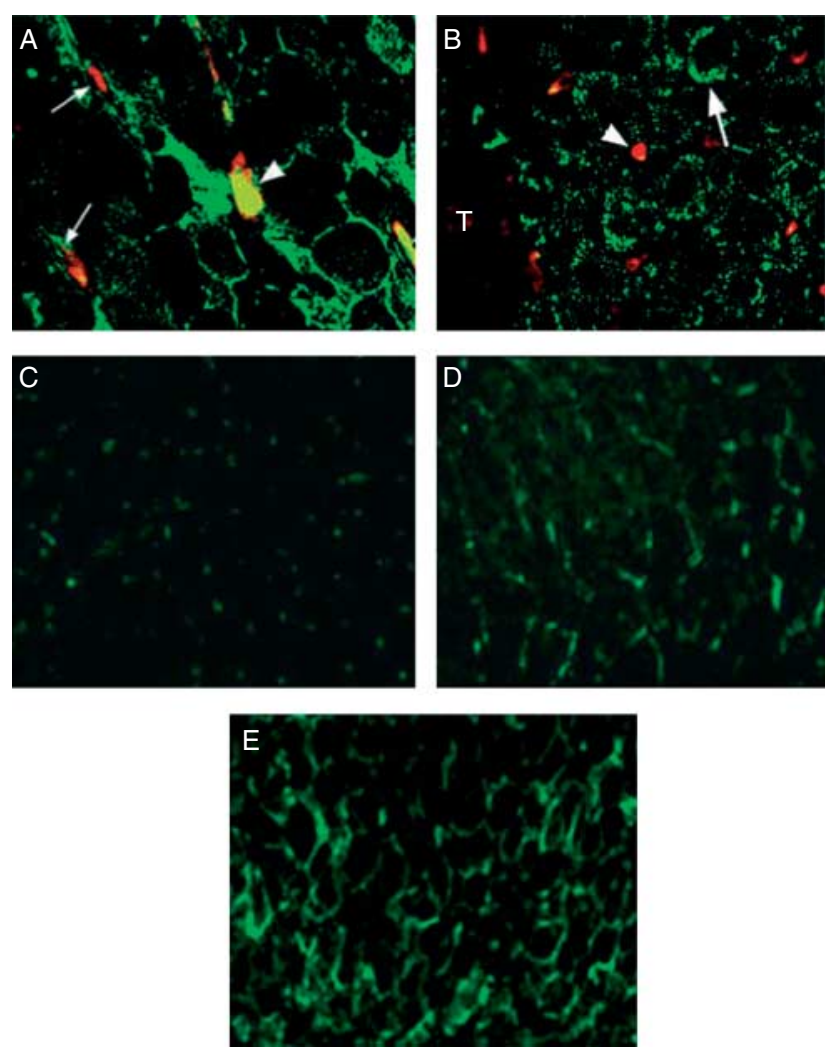

Figure $4 \mathrm{Immunohistochemical} \mathrm{staining} \mathrm{of} \mathrm{TJ}$ and $\mathrm{AJ}$ proteins in the mid-luteal human corpus luteum. (A) Occludin (dual staining with green fluorescence CD31 and red fluorescence Occludin), (B) Claudin 1 (dual staining with green fluorescence CD31 and red fluorescence Claudin 1), (C) VE-Cadherin (green fluorescence), (D) Claudin 5 (green fluorescence), and (E) Nectin 2 (green fluorescence) (Herr et al. 2013). 
the release of progesterone. However, in the case of OHSS, it can cause an escape of fluids from the peritoneal vessels into the abdominal cavity, resulting in ascites or pleural effusion. As this complication is due to VEGF, this factor might be a target for therapeutical approaches in order to treat patients with severe OHSS. Finally, in addition to well-established treatment, such as dopamine or metformin, there may be alternative management methods for severe OHSS. Basic knowledge of pathophysiology can help to treat OHSS but prevention is better than cure with mild stimulation regimes.

\section{Declaration of interest}

The authors declare that there is no conflict of interest that could be perceived as prejudicing the impartiality of the review.

\section{Funding}

This review did not receive any specific grant from any funding agency in the public, commercial or not-for-profit sector.

\section{References}

Akutagawa N, Nishikawa A, Iwasaki M, Fujimoto T, Teramoto $M$, Kitajima Y, Endo T, Shibuya M \& Kudo R 2002 Expression of vascular endothelial growth factor and E-cadherin in human ovarian cancer: association with ascites fluid accumulation and peritoneal dissemination in mouse ascites model. Japanese Journal of Cancer Research 93 644-651. (doi:10.1111/j.1349-7006.2002.tb01302.x)

Albert C, Garrido N, Mercader A, Rao CV, Remohi J, Simon C \& Pellicer A 2002 The role of endothelial cells in the pathogenesis of ovarian hyperstimulation syndrome. Molecular Human Reproduction 8 409-418. (doi:10.1093/molehr/8.5.409)

Alexander JS \& Elrod JW 2002 Extracellular matrix, junctional integrity and matrix metalloproteinase interactions in endothelial permeability regulation. Journal of Anatomy 200 561-574. (doi:10.1046/j.1469-7580. 2002.00057.x)

Baird DD, Weinberg CR, McConnaughey DR \& Wilcox AJ 2003 Rescue of the corpus luteum in human pregnancy. Biology of Reproduction 68 448-456. (doi:10.1095/biolreprod.102.008425)

Bazzoni G \& Dejana E 2004 Endothelial cell-to-cell junctions: molecular organization and role in vascular homeostasis. Physiological Reviews 84 869-901. (doi:10.1152/physrev.00035.2003)

Butt AM, Feng D, Nasrullah I, Tahir S, Idrees M, Tong Y \& Lu J 2012 Computational identification of interplay between phosphorylation and $O$ - $\beta$-glycosylation of human occludin as potential mechanism to impair hepatitis C virus entry. Infection, Genetics and Evolution 12 1235-1245. (doi:10.1016/j.meegid.2012.04.001)

Carmeliet P, Lampugnani MG, Moons L, Breviario F, Compernolle V, Bono F, Balconi G, Spagnuolo R, Oosthuyse B, Dewerchin M et al. 1999 Targeted deficiency or cytosolic truncation of the VE-cadherin gene in mice impairs VEGF-mediated endothelial survival and angiogenesis. Cell 98 147-157. (doi:10.1016/S0092-8674(00)81010-7)

Cavey M, Rauzi M, Lenne PF \& Lecuit T 2008 A two-tiered mechanism for stabilization and immobilization of E-cadherin. Nature 453 751-756. (doi:10.1038/nature06953)

Chitaev NA \& Troyanovsky SM 1998 Adhesive but not lateral E-cadherin complexes require calcium and catenins for their formation. Journal of Cell Biology 142 837-846. (doi:10.1083/jcb.142.3.837)

Dejana E 2004 Endothelial cell-cell junctions: happy together. Nature Reviews. Molecular Cell Biology 5 261-270. (doi:10.1038/nrm1357)
Dejana E, Orsenigo F, Molendini C, Baluk P \& McDonald DM 2009a Organization and signaling of endothelial cell-to-cell junctions in various regions of the blood and lymphatic vascular trees. Cell and Tissue Research 335 17-25. (doi:10.1007/s00441-008-0694-5)

Dejana E, Tournier-Lasserve E \& Weinstein BM 2009b The control of vascular integrity by endothelial cell junctions: molecular basis and pathological implications. Developmental Cell 16 209-221. (doi:10.1016/j.devcel.2009.01.004)

Del Canto F, Sierralta W, Kohen P, Munoz A, Strauss JF III \& Devoto L 2007 Features of natural and gonadotropin-releasing hormone antagonistinduced corpus luteum regression and effects of in vivo human chorionic gonadotropin. Journal of Clinical Endocrinology and Metabolism 92 4436-4443. (doi:10.1210/jc.2007-0125)

Delvigne A \& Rozenberg S 2002 Systematic review of data concerning etiopathology of ovarian hyperstimulation syndrome. International Journal of Fertility and Women's Medicine 47 211-226.

Delvigne A \& Rozenberg S 2003 Review of clinical course and treatment of ovarian hyperstimulation syndrome (OHSS). Human Reproduction Update 9 77-96. (doi:10.1093/humupd/dmg005)

Dickinson RE, Myers M \& Duncan WC 2008 Novel regulated expression of the SLIT/ROBO pathway in the ovary: possible role during luteolysis in women. Endocrinology 149 5024-5034. (doi:10.1210/en.2008-0204)

Dickinson RE, Stewart AJ, Myers M, Millar RP \& Duncan WC 2009 Differential expression and functional characterization of luteinizing hormone receptor splice variants in human luteal cells: implications for luteolysis. Endocrinology 150 2873-2881. (doi:10.1210/en.2008-1382)

Duncan WC, Gay E \& Maybin JA 2005 The effect of human chorionic gonadotrophin on the expression of progesterone receptors in human luteal cells in vivo and in vitro. Reproduction 130 83-93. (doi:10.1530/ rep.1.00216)

Errede M, Girolamo F, Ferrara G, Strippoli M, Morando S, Boldrin V, Rizzi M, Uccelli A, Perris R, Bendotti C et al. 2012 Blood-brain barrier alterations in the cerebral cortex in experimental autoimmune encephalomyelitis. Journal of Neuropathology and Experimental Neurology 71 840-854. (doi:10.1097/NEN.0b013e31826ac110)

Esser S, Lampugnani MG, Corada M, Dejana E \& Risau W 1998 Vascular endothelial growth factor induces VE-cadherin tyrosine phosphorylation in endothelial cells. Journal of Cell Science 111 1853-1865.

Fatemi HM, Popovic-Todorovic B, Papanikolaou E, Donoso P \& Devroey P 2007 An update of luteal phase support in stimulated IVF cycles. Human Reproduction Update 13 581-590. (doi:10.1093/humupd/dmm021)

Fraser HM \& Duncan WC 2005 Vascular morphogenesis in the primate ovary. Angiogenesis 8 101-116. (doi:10.1007/s10456-005-9004-y)

Fraser HM \& Lunn SF 2000 Angiogenesis and its control in the female reproductive system. British Medical Bulletin 56 787-797. (doi:10.1258/ 0007142001903364)

Fraser HM \& Lunn SF 2001 Regulation and manipulation of angiogenesis in the primate corpus luteum. Reproduction 121 355-362. (doi:10.1530/ rep.0.1210355)

Fraser HM, Lunn SF, Harrison DJ \& Kerr JB 1999 Luteal regression in the primate: different forms of cell death during natural and gonadotropin-releasing hormone antagonist or prostaglandin analogue-induced luteolysis. Biology of Reproduction 61 1468-1479. (doi:10.1095/ biolreprod61.6.1468)

Fraser HM, Bell J, Wilson H, Taylor PD, Morgan K, Anderson RA \& Duncan WC 2005 Localization and quantification of cyclic changes in the expression of endocrine gland vascular endothelial growth factor in the human corpus luteum. Journal of Clinical Endocrinology and Metabolism 90 427-434. (doi:10.1210/jc.2004-0843)

Fujibe M, Chiba H, Kojima T, Soma T, Wada T, Yamashita T \& Sawada N 2004 Thr203 of claudin-1, a putative phosphorylation site for MAP kinase, is required to promote the barrier function of tight junctions. Experimental Cell Research 295 36-47. (doi:10.1016/j.yexcr.2003. 12.014)

Furuse M \& Tsukita S 2006 Claudins in occluding junctions of humans and flies. Trends in Cell Biology 16 181-188. (doi:10.1016/j.tcb.2006. 02.006)

Gavard J \& Gutkind JS 2008 VE-cadherin and claudin-5: it takes two to tango. Nature Cell Biology 10 883-885. (doi:10.1038/ncb0808-883)

Gelety TJ \& Chaudhuri G 1992 Prostaglandins in the ovary and fallopian tube. Baillière's Clinical Obstetrics and Gynaecology 6 707-729. 
Gomez R, Ferrero H, Delgado-Rosas F, Gaytan M, Morales C, Zimmermann RC, Simon C, Gaytan F \& Pellicer A 2011 Evidences for the existence of a low dopaminergic tone in polycystic ovarian syndrome: implications for OHSS development and treatment. Journal of Clinical Endocrinology and Metabolism 96 2484-2492. (doi:10.1210/jc.2011-0075)

Groten T, Fraser HM, Duncan WC, Konrad R, Kreienberg R \& Wulff C 2006 Cell junctional proteins in the human corpus luteum: changes during the normal cycle and after HCG treatment. Human Reproduction $\mathbf{2 1}$ 3096-3102. (doi:10.1093/humrep/del286)

Herr D, Sallmann A, Bekes I, Konrad R, Holzheu I, Kreienberg R \& Wulff C 2012 VEGF induces ascites in ovarian cancer patients via increasing peritoneal permeability by downregulation of Claudin 5. Gynecologic Oncology 127 210-216. (doi:10.1016/j.ygyno.2012.05.002)

Herr D, Fraser HM, Konrad R, Holzheu I, Kreienberg R \& Wulff C 2013 Human chorionic gonadotropin controls luteal vascular permeability via vascular endothelial growth factor by down-regulation of a cascade of adhesion proteins. Fertility and Sterility 99 1749-1758 (e1746). (doi:10.1016/j.fertnstert.2013.01.120)

Illingworth DV \& Heap RB 1971 A decrease in the metabolic clearance rate of progesterone in the coypu during pregnancy. Journal of Reproduction and Fertility 27 492-494. (doi:10.1530/jrf.0.0270492)

Kametani Y \& Takeichi M 2007 Basal-to-apical cadherin flow at cell junctions. Nature Cell Biology 9 92-98. (doi:10.1038/ncb1520)

Kawagishi R, Tahara M, Morishige K, Sakata M, Tasaka K, Ikeda W, Morimoto K, Takai Y \& Murata Y 2005 Expression of nectin-2 in mouse granulosa cells. European Journal of Obstetrics, Gynecology, and Reproductive Biology 121 71-76. (doi:10.1016/j.ejogrb.2004.12.019)

Kitajima Y, Endo T, Nagasawa K, Manase K, Honnma H, Baba T, Hayashi T, Chiba H, Sawada N \& Saito T 2006 Hyperstimulation and a gonadotropin-releasing hormone agonist modulate ovarian vascular permeability by altering expression of the tight junction protein claudin5. Endocrinology 147 694-699. (doi:10.1210/en.2005-0700)

Klemetti R, Sevon T, Gissler M \& Hemminki E 2005 Complications of IVF and ovulation induction. Human Reproduction 20 3293-3300. (doi:10.1093/humrep/dei253)

Kumar P, Sait SF, Sharma A \& Kumar M 2011 Ovarian hyperstimulation syndrome. Journal of Human Reproductive Sciences 4 70-75. (doi:10.4103/0974-1208.86080)

van de Lagemaat R, Raafs BC, van Koppen C, Timmers CM, Mulders SM \& Hanssen RG 2011 Prevention of the onset of ovarian hyperstimulation syndrome (OHSS) in the rat after ovulation induction with a low molecular weight agonist of the LH receptor compared with hCG and rec-LH. Endocrinology 152 4350-4357. (doi:10.1210/en.2011-1077)

Lampe PD \& Lau AF 2004 The effects of connexin phosphorylation on gap junctional communication. International Journal of Biochemistry \& Cell Biology 36 1171-1186. (doi:10.1016/S1357-2725(03)00264-4)

Lampugnani MG, Orsenigo F, Gagliani MC, Tacchetti C \& Dejana E 2006 Vascular endothelial cadherin controls VEGFR-2 internalization and signaling from intracellular compartments. Journal of Cell Biology $\mathbf{1 7 4}$ 593-604. (doi:10.1083/jcb.200602080)

Langbein L, Grund C, Kuhn C, Praetzel S, Kartenbeck J, Brandner JM, Moll I \& Franke WW 2002 Tight junctions and compositionally related junctional structures in mammalian stratified epithelia and cell cultures derived therefrom. European Journal of Cell Biology 81 419-435. (doi:10.1078/0171-9335-00270)

Leach L, Babawale MO, Anderson M \& Lammiman M 2002 Vasculogenesis, angiogenesis and the molecular organisation of endothelial junctions in the early human placenta. Journal of Vascular Research 39 246-259. (doi:10.1159/000063690)

Matsubara H, Ikuta K, Ozaki Y, Suzuki Y, Suzuki N, Sato T \& Suzumori K 2000 Gonadotropins and cytokines affect luteal function through control of apoptosis in human luteinized granulosa cells. Journal of Clinical Endocrinology and Metabolism 85 1620-1626. (doi:10.1210/jcem.85. 4.6509)

Misrahi M, Beau I, Ghinea N, Vannier B, Loosfelt H, Meduri G, Vu Hai MT \& Milgrom E 1996 The LH/CG and FSH receptors: different molecular forms and intracellular traffic. Molecular and Cellular Endocrinology 125 161-167. (doi:10.1016/S0303-7207(96)03953-6)

Morita K, Sasaki H, Furuse M \& Tsukita S 1999 Endothelial claudin: claudin-5/TMVCF constitutes tight junction strands in endothelial cells. Journal of Cell Biology 147 185-194. (doi:10.1083/jcb.147.1.185)
Nakhuda GS, Zimmermann RC, Bohlen P, Liao F, Sauer MV \& Kitajewski J 2005 Inhibition of the vascular endothelial cell (VE)-specific adhesion molecule VE-cadherin blocks gonadotropin-dependent folliculogenesis and corpus luteum formation and angiogenesis. Endocrinology 146 1053-1059. (doi:10.1210/en.2004-0977)

Nelson WJ \& Veshnock PJ 1987 Ankyrin binding to $\left(\mathrm{Na}^{++} \mathrm{K}^{+}\right)$ATPase and implications for the organization of membrane domains in polarized cells. Nature 328 533-536. (doi:10.1038/328533a0)

Neulen J, Raczek S, Pogorzelski M, Grunwald K, Yeo TK, Dvorak HF, Weich HA \& Breckwoldt M 1998 Secretion of vascular endothelial growth factor/vascular permeability factor from human luteinized granulosa cells is human chorionic gonadotrophin dependent. Molecular Human Reproduction 4 203-206. (doi:10.1093/molehr/4.3.203)

Nitta T, Hata M, Gotoh S, Seo Y, Sasaki H, Hashimoto N, Furuse M \& Tsukita S 2003 Size-selective loosening of the blood-brain barrier in claudin-5-deficient mice. Journal of Cell Biology 161 653-660. (doi:10.1083/jcb.200302070)

Papanikolaou EG, Tournaye H, Verpoest W, Camus M, Vernaeve V, Van Steirteghem A \& Devroey P 2005 Early and late ovarian hyperstimulation syndrome: early pregnancy outcome and profile. Human Reproduction 20 636-641. (doi:10.1093/humrep/deh638)

Peppi M \& Ghabriel MN 2004 Tissue-specific expression of the tight junction proteins claudins and occludin in the rat salivary glands. Journal of Anatomy 205 257-266. (doi:10.1111/j.0021-8782.2004. 00332.x)

Pietrowski D, Szabo L, Sator M, Just A \& Egarter C 2012 Ovarian hyperstimulation syndrome is correlated with a reduction of soluble VEGF receptor protein level and a higher amount of VEGF-A. Human Reproduction 27 196-199. (doi:10.1093/humrep/der349)

Rodewald M, Herr D, Fraser HM, Hack G, Kreienberg R \& Wulff C 2007 Regulation of tight junction proteins occludin and claudin 5 in the primate ovary during the ovulatory cycle and after inhibition of vascular endothelial growth factor. Molecular Human Reproduction 13 781-789. (doi:10.1093/molehr/gam066)

Rodewald M, Herr D, Duncan WC, Fraser HM, Hack G, Konrad R, Gagsteiger F, Kreienberg R \& Wulff C 2009 Molecular mechanisms of ovarian hyperstimulation syndrome: paracrine reduction of endothelial claudin 5 by hCG in vitro is associated with increased endothelial permeability. Human Reproduction 24 1191-1199. (doi:10.1093/ humrep/den479)

Schmitt M, Horbach A, Kubitz R, Frilling A \& Haussinger D 2004 Disruption of hepatocellular tight junctions by vascular endothelial growth factor (VEGF): a novel mechanism for tumor invasion. Journal of Hepatology 41 274-283. (doi:10.1016/j.jhep.2004.04.035)

Soares SR 2012 Etiology of OHSS and use of dopamine agonists. Fertility and Sterility 97 517-522. (doi:10.1016/j.fertnstert.2011.12.046)

Stocco C, Telleria C \& Gibori G 2007 The molecular control of corpus luteum formation, function, and regression. Endocrine Reviews $\mathbf{2 8}$ 117-149. (doi:10.1210/er.2006-0022)

Sundfeldt K, Piontkewitz Y, Billig H \& Hedin L 2000 E-cadherin-catenin complex in the rat ovary: cell-specific expression during folliculogenesis and luteal formation. Journal of Reproduction and Fertility 118 375-385.

Taylor PD, Wilson H, Hillier SG, Wiegand SJ \& Fraser HM 2007 Effects of inhibition of vascular endothelial growth factor at time of selection on follicular angiogenesis, expansion, development and atresia in the marmoset. Molecular Human Reproduction 13 729-736. (doi:10.1093/ molehr/gam056)

Van Itallie CM \& Anderson JM 2006 Claudins and epithelial paracellular transport. Annual Review of Physiology 68 403-429. (doi:10.1146/ annurev.physiol.68.040104.131404)

Villasante A, Pacheco A, Ruiz A, Pellicer A \& Garcia-Velasco JA 2007 Vascular endothelial cadherin regulates vascular permeability: implications for ovarian hyperstimulation syndrome. Journal of Clinical Endocrinology and Metabolism 92 314-321. (doi:10.1210/jc.20061231)

Walz A, Keck C, Weber H, Kissel C \& Pietrowski D 2005 Effects of luteinizing hormone and human chorionic gonadotropin on corpus luteum cells in a spheroid cell culture system. Molecular Reproduction and Development 72 98-104. (doi:10.1002/mrd.20325)

Wang TH, Horng SG, Chang CL, Wu HM, Tsai YJ, Wang HS \& Soong YK 2002 Human chorionic gonadotropin-induced ovarian hyperstimulation 
syndrome is associated with up-regulation of vascular endothelial growth factor. Journal of Clinical Endocrinology and Metabolism 87 3300-3308. (doi:10.1210/jcem.87.7.8651)

Willis CL, Camire RB, Brule SA \& Ray DE 2013 Partial recovery of the damaged rat blood-brain barrier is mediated by adherens junction complexes, extracellular matrix remodeling and macrophage infiltration following focal astrocyte loss. Neuroscience 250 773-785. (doi:10. 1016/j.neuroscience.2013.06.061)

Wright TJ, Leach L, Shaw PE \& Jones P 2002 Dynamics of vascular endothelial-cadherin and $\beta$-catenin localization by vascular endothelial growth factor-induced angiogenesis in human umbilical vein cells. Experimental Cell Research 280 159-168. (doi:10.1006/excr.2002. 5636)

Wulff C, Wilson H, Largue P, Duncan WC, Armstrong DG \& Fraser HM 2000 Angiogenesis in the human corpus luteum: localization and changes in angiopoietins, tie-2, and vascular endothelial growth factor messenger ribonucleic acid. Journal of Clinical Endocrinology and Metabolism 85 4302-4309.

Wulff C, Dickson SE, Duncan WC \& Fraser HM 2001 a Angiogenesis in the human corpus luteum: simulated early pregnancy by HCG treatment is associated with both angiogenesis and vessel stabilization. Human Reproduction 16 2515-2524. (doi:10.1093/humrep/16.12.2515)

Wulff C, Wiegand SJ, Saunders PT, Scobie GA \& Fraser HM $2001 b$ Angiogenesis during follicular development in the primate and its inhibition by treatment with truncated Flt-1-Fc (vascular endothelial growth factor Trap(A40)). Endocrinology 142 3244-3254.

Wulff C, Wilson H, Rudge JS, Wiegand SJ, Lunn SF \& Fraser HM 2001 C Luteal angiogenesis: prevention and intervention by treatment with vascular endothelial growth factor Trap(A40). Journal of Clinical Endocrinology and Metabolism 86 3377-3386.
Wulff C, Wilson H, Wiegand SJ, Rudge JS \& Fraser HM 2002 Prevention of thecal angiogenesis, antral follicular growth, and ovulation in the primate by treatment with vascular endothelial growth factor Trap R1R2. Endocrinology 143 2797-2807. (doi:10.1210/endo.143. 7.8886)

Yap AS, Brieher WM \& Gumbiner BM 1997 Molecular and functional analysis of cadherin-based adherens junctions. Annual Review of Cell and Developmental Biology 13 119-146. (doi:10.1146/annurev.cellbio. 13.1.119)

You K, Xu X, Fu J, Xu S, Yue X, Yu Z \& Xue X 2012 Hyperoxia disrupts pulmonary epithelial barrier in newborn rats via the deterioration of occludin and ZO-1. Respiratory Research 13 36. (doi:10.1186/14659921-13-36)

Zacchigna S, Tasciotti E, Kusmic C, Arsic N, Sorace O, Marini C, Marzullo P, Pardini S, Petroni D, Pattarini L et al. 2007 In vivo imaging shows abnormal function of vascular endothelial growth factor-induced vasculature. Human Gene Therapy 18 515-524. (doi:10.1089/hum. 2006.162)

Zhu Y, Maric J, Nilsson M, Brannstrom M, Janson PO \& Sundfeldt K 2004 Formation and barrier function of tight junctions in human ovarian surface epithelium. Biology of Reproduction 71 53-59. (doi:10.1095/ biolreprod.103.022913)

Received 9 July 2013

First decision 30 August 2013

Revised manuscript received 18 March 2014

Accepted 9 October 2014 